\title{
ENCONTROS INTERGERACIONAIS MEDIADOS POR IMAGENS E MEMÓRIAS DO BAIRRO E DA ESCOLA
}

\author{
INTERGENERATIONAL MEETINGS MEDIATED BY IMAGES AND \\ MEMORIES OF THE NEIGHBORHOOD AND OF THE SCHOOL
}

DOI: http://dx.doi.org/10.5965/1984317816012020268

\author{
Maria Angélica Vago-Soares \\ Universidade Federal do Espírito Santo \\ angelicavago@gmail.com
}

Gerda Margit Schütz-Foerste

Universidade Federal do Espírito Santo gerda foerste@yahoo.com.br

\begin{abstract}
RESUMO
Este artigo descreve o processo de produção de narrativas intergeracionais desenvolvido com crianças, adolescentes, adultos e velhos. Trata-se de etapa de investigação de doutorado baseada em etnografia realizada na Escola Municipal de Ensino Fundamental Sonia Regina Gomes Rezende Franco, bairro Serra Dourada I, Serra (ES), em que 34 crianças/adolescentes de $6 \% 7^{\circ}$ ano foram envolvidas em um projeto de ensino de Arte que se desenrolou no âmbito das aulas de Arte e História, ao longo de três semestres letivos. Após apreciar vídeos e fotografias e visitar alguns dos espaços culturais da cidade, as crianças/adolescentes remeteram o olhar ao bairro e, desejando saber mais sobre ambos, sugeriram conversa com moradores antigos, o que se concretizou com a roda de conversa. A experiência fundamenta-se em Ciavatta (2007), Benjamin (2012), Bosi (1994), Brandão (1984, 2003, 2007), Fonseca da Silva e Schlichta (2015), Freire (2014), Halbwachs (2003), Mannheim (1952, 2014) e Schütz-Foerste (2004). Os resultados mostram que a roda de conversa intergeracional é possibilidade para cultivar imagens e memórias, promovendo o ato de narrar que inclui velhos, adultos e crianças e adolescentes, que se encontram e compartilham suas distintas culturas, sem, contudo, estabelecer hierarquização entre elas.
\end{abstract}

Palavras-chave: Mediação da linguagem. Igualdade entre gerações. Educação para o diálogo. Ensino da arte.

\begin{abstract}
This article describes the process of producing intergenerational narratives developed with children, adolescents, adults and elderly. This is one stage of an ethnographic-based doctoral research, carried out at the Sonia Regina Gomes Rezende Franco Municipal Elementary School, in Serra Dourada I neighborhood - municipality of Serra/ES. 34 children and adolescents from the 7th and 8th grades were involved in an Art teaching project that took place within the classes of Art and History, during three semesters. After apprizing videos and photos, and visiting some of the city's cultural spaces, the children looked back at the neighborhood and, wishing to learn more about both, suggested a talk with old residents, which was realized using the dialogue circle method. The experience was based on Ciavatta (2007), Benjamin (2012), Bosi (1994), Brandão (1984, 2003, 2007), Fonseca da Silva and Schlichta (2015), Freire (2014), Halbwachs (2003), Mannheim (1952, 2014) and SchützFoerste (2004). The results show that the intergenerational dialogue circle is a possibility to cultivate images and memories, promoting narratives that include old-aged people, adults, adolescents, and children, who meet and share their different cultures, without establishing, however, hierarchy between them.
\end{abstract}

Keywords: Language mediation. Equality between generations. Education for dialogue. Art teaching. 


\section{INTRODUÇÃO}

Como parte de um a investigação que se estendeu por três semestres letivos em uma escola pública situada em área urbana de um município metropolitano (Serra - ES), a experiência aqui destacada tem como premissa a ideia de que a escola, a cidade e o bairro são espaços que possibilitam aos sujeitos a compartilha de conhecimentos e a (re)construção de práticas. Ainda que neles convivam distintas gerações (crianças, adolescentes, adultos profissionais da educação, adultos e velhos do bairro), notamos a escassez de encontros que lhes permitam o exercício da escuta e da fala e, por consequência, o sentimento de inclusão na vida social.

O movimento de inclusão precisa mirar, sobretudo, velhos e crianças. Com as discussões promovidas pela sociologia da infância, estas são vistas como sujeitos ativos, ocupando, portanto, lugar nas decisões sociais (SARMENTO, acesso em 10 mar. 2017). Porém, percebemos que a cultura vigente ainda as situa como geração que deve obediência aos adultos, o que nem sempre permite que elas sejam de fato escutadas.

Sobre o velho, Bosi (1994) sublinha sua posição à margem da vida social, de modo que, frequentemente, este, a quem foi dado o papel de narrar, não encontra suporte para sua obra, em especial, em um tempo em que as informações são distribuídas com tanta facilidade e rapidez. Todavia, adverte a autora que o velho é portador de memórias e narrativas que, trazidas à cena para serem conhecidas por outras gerações com as quais ele convive, possibilitam a ele e ao outro (re)criar suas histórias.

Por isso, é preciso oportunizar momentos de escuta também a estes sujeitos, pois eles têm autoridade ao narrar, contam suas histórias com propriedade, conectam-se ao presente (BENJAMIN, 2012). Nesse sentido, na etapa do estudo aqui destacada, a escola foi espaço de articulação com outros (com)textos, forma de escrita que tem o intuito de "[...] chamar a atenção aos contextos e aos diversos textos e sujeitos que o caracterizam. Texto tendo em vista não apenas o escrito, mas as falas, silêncios" (VAGO-SOARES, 2015, p. 17). Os (com)textos aqui destacados são a escola, o bairro e um de seus moradores mais antigos. Nessa dinâmica, 
escola e bairro se estabelecem como lugar de produzir narrativas conectadas à história dos sujeitos, independentemente da geração em que estes se situem.

Neste estudo, tal como em Mannheim (2004), o conceito de geração não se reduz a um grupo cuja data de nascimento se dá em um tempo comum, mas se fundamenta na partilha de acontecimentos sociais e experiências significativas que originam uma consciência comum ao longo da vida. Trata-se, assim, de uma categoria analítica das mudanças sociais e, nessa perspectiva, Sarmento (2005, p. 375-376) pontua que os encontros intergeracionais "[...] têm constituído um aspecto vital na mudança social [...]", tanto nas infâncias quanto na vida dos adultos e também dos velhos, pois todos são por eles impactados.

O intercâmbio de narrativas aqui analisado foi produzido por meio do cultivo de imagens e memórias (artísticas, sociais, políticas etc.), assumindo a configuração de roda de conversa. A proposta toma como referência o "camponês sedentário" e o "marinheiro comerciante" (BENJAMIN, 2012), objetivando perceber e discutir acerca das memórias e imagens em (com)textos educativos. Nesse processo, os envolvidos provocaram e foram provocados a pensar, discutir e analisar sobre si, suas narrativas, seu lugar...

Para Benjamin (2012, p. 222), o repertório do bom narrador contém experiências de arte, culturas e tradições, próprias e alheias, com vestígios "[...] presentes de muitas maneiras nas coisas narradas, se não na qualidade de quem as viveu, ao menos na de quem as relata [...]". Assim, aprender e ensinar não são atos solitários, muito pelo contrário, são atos de gentileza, de compartir, que se dão entre gerações. Eis outra premissa que sustenta a experiência em análise, a qual é parte de um projeto de ensino da Arte, enredado a aspectos socioculturais, históricos e políticos da escola onde foi desenvolvido.

Nesse sentido, sujeitos são protagonistas de suas histórias. As crianças, adolescentes, profissionais da escola e o morador do bairro, que participaram do encontro intergeracional, aqui destacado, trouxeram narrativas emaranhadas de tramas por eles experienciadas. Reconhecer-se parte desse todo em sua comunidade é relevante para o cultivo das artes e das culturas, evitando sua marginalização e invisibilidade, acolhendo-as e incluindo-as no espaço escolar. 
Nas seções a seguir, aprofundamos a fundamentação teórica sobre encontros intergeracionais, mediação das imagens e das memórias e rodas de conversa. $\mathrm{Na}$ sequência, caracterizamos o processo de preparação e realização da roda de conversa em que ocorreu o encontro intergeracional analisado. Por fim, trazemos as considerações que a experiência permite-nos delinear.

\section{TROCAS INTERGERACIONAIS}

Em função das transformações tecnológicas, as gerações contemporâneas podem participar de mais culturas, porém, em caráter mais superficial, pela efemeridade do nosso tempo. Não há como mensurar os ganhos e perdas, mas o fato é que a educação precisa atuar como mediadora nas trocas geracionais.

Neste trabalho, nosso entendimento de geração está em consonância com a visão de Mannheim (1952, p. 69, tradução nossa), para quem ela.

[...] não é um grupo concreto no sentido de uma comunidade, isto é, um grupo que não pode existir sem os seus membros terem um conhecimento concreto uns dos outros, e que cessa de existir como uma unidade mental e espiritual assim que é abolida a proximidade física. Por outro lado, ela não é de modo algum comparável a associações tais como as organizações formadas para um objetivo específico [...].

Sendo assim, tal como este pensador, entendemos geração como fenômeno social, vinculada a certos modos similares de vários sujeitos, dentro de um todo social. Acrescenta ele que "[...] os membros de qualquer uma das gerações, apenas podem participar de uma sessão temporalmente limitada do processo histórico [...]" (MANNHEIM, 1952, p. 74, tradução nossa), daí a importância de cultivar tradições e culturas. Em síntese, a geração é conceito que não se reduz à data de nascimento em um tempo comum, fundamentando-se na partilha de fatos sociais e experiências significativas que originam consciência comum ao longo da vida.

Se as gerações são construção social, datada e localizada, assim também são as infâncias, as juventudes e as velhices. Siqueira (2011) rompe a ideia de cronologia, segregação em idades ou etapas, entendendo a infância como tempo vivido na interação, perpassado por aspectos sociais e culturais, também produzindo 
cultura. Nessa perspectiva, infância não é "[...] apenas uma etapa do desenvolvimento humano, é a intensidade da duração, expressando a forma como cada um experiencia a vida [...]" (ASSIS, 2012, acesso em 14 jan. 2019), pois ser criança também independe da idade; depende, sim, das relações do sujeito com a produção humana. No diálogo com outras gerações, as crianças delineiam modos de ser, perceber e estar no mundo, "[...] como sujeitos do conhecimento e, portanto, em condições de atuar criticamente nos modos de pensar e de produzir [...]" (VASCONCELLOS, 2007, p. 10).

Também considerada categoria social, a velhice tem "[...] um estatuto contingente, pois cada sociedade vive de forma diferente o declínio biológico do homem [...]" (BOSI, 1994, p. 77). Ademais, como o cuidado com os velhos passou a ocorrer externamente ao ambiente familiar, há menos oportunidade de compartilha e escuta de suas memórias. Assim, é fundamental que a escola promova encontros intergeracionais que incluam as narrativas desses sujeitos, pois, conforme assevera Benjamin (2013, p. 65), a educação constitui, prioritariamente, "a indispensável ordenação das relações entre as gerações".

$\mathrm{Na}$ escola, transitamos pelas diferentes gerações, continuamente (MANNHEIM, 2004). Mesmo em silêncio, as gerações interagem, processo que, segundo Vigotski (2010, p. 291), abarca dos sete aos 14 anos, quando a criança "[...] adquire todas as habilidades necessárias ao adulto [...]". Rosa (2011, p. 35) salienta que a experiência criança-adulto no ambiente da escola não pode ser substituída "[...] pelo conhecimento objetivo, técnico, especializado [...]". Daí a relevância do cultivo de tradições, imagens e memórias dos sujeitos e de seus espaços, da aprendizagem a partir das narrativas, em que "[...] o novo convive com o velho, proporcionando aprendizagem criadora de uma experiência recheada de sentido e imaginação" (ROSA, 2011, p. 39).

Nessa perspectiva, sujeitos ausentes da escola foram incluídos e escutados na pesquisa da qual parte do percurso é aqui relatada. Nesse processo, entendemos que o intergeracionismo se constitui na compartilha, reiterando a dimensão do ensinar e do aprender, em que as gerações caminham juntas - sem dar ênfase a quem ensina ou a quem aprende, entendendo essas partes sem hierarquia. Assim, 
nas trocas entre as gerações e entre pares, os participantes misturaram os atos criativos às suas emoções, entrelaçando os arcabouços social, cultural e histórico do (com)texto em que construíram suas narrativas.

Em síntese, perceber as relações intergeracionais é entender que as culturas estão emergindo em cada núcleo social, no nível micro ou macro. Compreender como se estabelecem tais construções é desafiador, pois, conforme Sarmento (2003), o processo de produção interpretativa é produzido por cada criança, adulto ou velho sempre de maneira singular.

\section{A MEDIAÇÃO DAS IMAGENS E DA MEMÓRIA NA ARTE DE NARRAR}

A produção humana se materializa em objetos, imagens, textos diversos. Nessas narrativas, artísticas ou não, há expressão humana que vêm das memórias de apropriações diversas que ocorrem nas relações cotidianas. Em suas experiências, a criança "[...] carrega consigo sua história e cultura, revelando, assim, uma plasticidade permanente nas formas que encontra para reinventar a realidade [...]" (ARAÚJO, 2005, p. 118). Em suas reinvenções, cria e recria a partir das memórias.

O encontro entre sujeitos de distintas gerações e com(textos) é também encontro de diferentes culturas. Porém, não se deve desqualificar qualquer que seja a cultura ou a arte presente na escola ou em seu entorno (BRANDÃO, 2007). Com base nessa premissa, é relevante pensar o ensino da Arte considerando a aula como espaço de trocas, centrado em narrativas que partem de questões concretas, problematizando-as e buscando meios de produzir conhecimentos que contribuam para o cultivo das imagens e memórias.

É necessário, portanto, pensar e repensar as ações propostas na escola, para que ela seja, todos os dias, espaço de reflexão e produção de mudanças da realidade, que devem começar por nós mesmos, para, então, serem sentidas na comunidade escolar. Por isso, a cada professor, em especial ao de Arte, cabe possibilitar momentos de escuta, da criança com seus pares, com os adultos da escola e do bairro, como também com os velhos. 
Como proposto por Camargo (2014), a memória imagética estabelece-se como elemento mediador, orientando os processos de conhecimento que são tecidos nas relações complexas no cotidiano escolar, potencializando as práticas diárias no contexto escolar entre as gerações. A partir das relações entre os sujeitos e a arte, os diálogos propostos no processo de ensinar e aprender, na escola ou em qualquer espaço, formam-se todos os que, de uma forma ou de outra, interagem. Tendo a arte como mediadora, a contribuição da educação se efetiva e as crianças têm a oportunidade de trocas de conhecimentos, o que implica ensinar-lhes

[...] a ver não só imagens, mas ver o outro, suas intenções, enfim, suas visões. A sala de aula, nesse caso, passa a ser entendida como lugar de interação, de diálogo entre sujeitos que se apropriam do conhecimento produzido pela humanidade [...] (FONSECA DA SILVA; SCHLICHTA, 2015, p. 12).

Assim, podemos entender como essencial para a formação humana a proposição de diálogos que imbriquem memórias e imagens relacionadas ao espaço-tempo vivido, não reduzindo ou esvaziando a educação à priorização dos conteúdos escolares previstos para cada segmento, perdendo de vista seu caráter cultural, pois "[...] uma pedagogia concreta é aquela que considera os educandos como indivíduos concretos, isto é, como síntese das relações sociais [...]" (SAVIANI, 2012, p. 79).

Saviani (2012) considera a educação como lugar privilegiado de práticas a partir do sujeito, da história humana. Segundo sua concepção, para que essa formação plena aconteça, o melhor caminho é mergulhar na própria história, permitir aos educandos vivenciar os momentos significativos da aventura temporal humana. Nesse sentido, como Fonseca da Silva e Schlichta (2015, p. 11-12), entendemos a imagem e as memórias como objetos de ensino-aprendizagem, pois,

[...] do ponto de vista do encaminhamento metodológico, [configuram] uma ação do professor vinculada a duas práticas em especial: a primeira, uma atividade permanente da leitura e interpretação de imagens, entendendo-as como pistas que revelam a história dos diferentes grupos sociais, de crianças, homens e mulheres, incluindo-se aí a do professor e de seus alunos, a história da arte e todas as histórias, que são sempre histórias de poder. A segunda prática, uma produção contínua e sistemática de imagens, desde desenhos, pinturas, gravuras, maquetes e até mapas, 
recortes, colagens etc. Na verdade, essas práticas estão interligadas e sua divisão tem por objetivo [...] ampliar e tornar mais clara a reflexão sobre a imagem e seus conteúdos.

Nas práticas com imagens e memórias, novos sentidos são produzidos, contribuindo para uma formação humana com repertórios mais amplos, em que as histórias individuais interligam-se à história coletiva. Em processo contínuo e ativo, a criança descobre meios para interagir e interferir nas situações cotidianas. Nessas interações, as gerações se encontram a todo o momento, no espaço escolar ou externamente a ele, havendo trocas, mesmo que não sejam percebidas de imediato, pois, no silêncio, o ser humano também está se reinventando.

Duarte (2012, p. 37) assevera que é necessário pensar os sujeitos para além de seu empirismo, como seres livres que interagem com tudo que está à sua volta, pois "[...] o ser humano é antes de tudo um ser vivo e a sociedade só pode existir em permanente intercâmbio com a natureza”. Dotados dessa constituição, apropriamonos de tudo de que participamos; guardamos em nossas memórias aquilo que antes fazia parte das memórias de outros, já que "[...] o lugar ocupado por um grupo não é como um quadro-negro no qual se escreve e depois se apaga números e figuras [...]" (HALBWACHS, 2003, p. 160).

Em diálogo com Fonseca da Silva e Schlichta (2015), compreendemos as imagens como parte do processo de formação humana, tendo em vista as reflexões desenvolvidas a partir dos encontros e apreciações orais, imagéticos (fotografias, escritas alfabéticas, artefatos, espaços ao vivo e em cores, vídeos etc.). Ao ser acessado, esse material traz à tona as memórias, o que também ocorre quando nos permitimos acessá-las mentalmente.

Também entendemos as memórias imbricadas a fatos pessoais e profissionais, ou seja, a lembranças diversas que fazem parte da individualidade de um sujeito, bem como da coletividade, de grupos aos quais ele pertence/pertenceu, considerando que, "[...] na medida em que os homens, simultaneamente, refletem sobre si e sobre o mundo, vão aumentando o campo de sua percepção [...]" (FREIRE, 2014, p. 99), logo, de suas práticas. 


\section{RODA DE CONVERSA E O ATO DE NARRAR}

A importância da escuta e do olhar evidencia-se quando pensamos a qualidade do processo educativo. Segundo Vigotski (2010, p. 448), "[...] para a educação atual não é tão importante ensinar certo volume de conhecimento quanto educar as habilidades para adquirir esses conhecimentos e utilizá-los [...]". Dessas habilidades, podemos mencionar a percepção, o olhar, a escuta e a interação com o outro e com o que nos rodeia, pois "[...] há uma relação dialética entre o comunicar e o conhecer, uma vez que ambos partilham de uma mesma condição: a que é dada pela linguagem [...]" (OLIVEIRA, 1996, p. 23).

Com o advento da tecnologia de compartilhamento via redes de informática, as informações chegam até nós em tempo real. Nesse cenário, "[...] rapidamente fazemos associações e reconstruímos situações e saberes sobre as práticas a partir das relações que estabelecemos entre as diferentes e, muitas vezes, caóticas informações [...]" (SCHÜTZ-FOERSTE, 2013, p. 187-188). Essa dinâmica de distribuição informacional extremamente veloz remete-nos às reflexões de Benjamin (2012, p. 219), para quem, apesar da riqueza de informações, "[...] somos pobres em histórias surpreendentes. A razão para tal é que todos os fatos já nos chegam impregnados de explicações [...]".

Em função disso, o desaparecimento da narrativa oral foi uma das preocupações do filósofo frankfurtiano, que observou o pouco tempo de que se dispunha, já nos anos 1930, para se escutar e contar histórias, destacando para a busca, por parte dos sujeitos, por abreviações, hoje tão frequentes nas narrativas das redes sociais. Apesar de o empobrecimento da narrativa ter se acentuado de lá para cá, compreendemos que os atores do cotidiano escolar possuem a arte de narrar, que se constitui no processo de observação-apreciação e em fazer o intercâmbio de experiências. Quanto mais o leitor-apreciador interage com as narrativas, com mais propriedade poderá estabelecer diálogos, rememorando suas experiências ou de outros, posto que as interações fazem parte das aproximações entre sujeitos e (com)textos.

Benjamin (2012) lança mão de duas metáforas para explicar a dinâmica das narrativas. A primeira é a do "camponês sedentário": ele supera dificuldades, se 
esforça, não desiste; continua no seu lugar de origem, conhece as histórias e tradições, culturas de si, do povo, logo, de seus lugares de pertencimento, que lhe foram transmitidas pelas gerações anteriores. A segunda metáfora trata do "marinheiro comerciante", que, a partir das viagens, incorpora a seu repertório muitos fatos e imagens, para contar e recontar suas histórias.

Para Benjamin (2012), um exemplo de grande narrador é encontrado na obra literária de Nikolai Leskov, por ser este um colecionador de muitas experiências, próprias e/ou alheias, durante sua trajetória de vida. Leskov (apud VÁSSINA, 2012, p. 213) destaca uma de suas inquietações: "nunca entendi e não entendo até hoje os sermões da imprensa dizendo que é preciso estudar o povo. É preciso simplesmente conhecer o povo como a própria vida, não estudando, mas vivendo-a". Inspirando-nos neste escritor, transpomos sua inquietação para o contexto da escola, assumindo que a aproximação do narrador com os (com)textos é uma maneira de produzir escutas que sejam links para a arte de narrar, como propõe Benjamin (2012).

Para pensar esses (com)textos, é preciso vivermos o cotidiano educativo, não apenas estudá-lo, afinal, "[...] a educação é alguma coisa que existe no povo, mesmo quando não há escola, em tudo o que ele faz e cria para ensinar e aprender [...]" (BRANDÃO, 1984, p. 90), sendo o povo protagonista de seus fazeres e saberes tradicionais (FREIRE, 2014). Essa compreensão contribui para ancorarmo-nos em propostas metodológicas baseadas na colaboração com os sujeitos da escola.

Nesse sentido a roda de conversa constituiu-se em instrumento valioso na pesquisa aqui relatada. A forma circular de conversas é prática educativa que, na perspectiva da educação libertadora proposta por Freire (1995), constitui um círculo de cultura, momento para escutar e ser escutado, na dimensão dialética, incorporada à afetividade, tendo em vista que "[...] o ato de conhecer envolve um movimento dialético que vai da ação à reflexão sobre ela [a ação] e, a partir disso, a uma nova ação [...]" (FREIRE, 2011, p. 80).

Hoje, notamos que tal prática é frequente na Educação Infantil, cujo currículo tem como eixos a interação e a brincadeira (BRASIL, 2010). O professor e as crianças sentam-se no chão e conversam sobre suas vidas e assuntos planejados 
pelo docente. No Ensino Fundamental, porém, até o mobiliário e a organização das salas são diferentes. Nessa transição, parece que a criança salta de uma infância a outra; as rodas de conversa pouco ou não mais acontecem.

Para Brandão (2003), as conversas abertas são melhores do que questionários prontos, pois com elas conhecemos coisas e casos, sentimentos e sentidos, os imaginários e os significados da vida. Assim, na experiência destacada neste trabalho, a roda de conversa foi usada para provocar a escuta e a fala, instigando o diálogo e funcionando como um espaço de formação no qual há a possibilidade de trocas, de maneira a não priorizar um narrador. A roda configurouse, ainda, como momento de cultivo das memórias da escola e do bairro em que ela se encontra, partindo da concepção de que o homem é "[...] sujeito e objeto na produção do conhecimento, não é um indivíduo isolado, mas um sujeito que realiza a história e nela se realiza [...]" (CIAVATTA, 2009, p. 25).

\section{DISCUSSÃO DAS NARRATIVAS PRODUZIDAS NO ENCONTRO INTERGERACIONAL}

\subsection{PREPARAÇÃo}

Reiteramos que, como parte de uma investigação mais longa, a experiência em análise é uma etapa de um projeto de ensino da Arte antecedida por apreciação de vídeos e fotografias da Serra (ES), cidade onde se localiza a escola, bem como por visitas das crianças/adolescentes a alguns de seus espaços culturais. Depois disso, elas remeteram seu olhar para o bairro que abriga a escola e, curiosas para saber mais sobre ambos, sugeriram uma conversa com moradores antigos. Nascia com elas, portanto, o embrião do encontro intergeracional aqui relatado, ocorrido em uma roda de conversa.

A partir disso, dialogamos a respeito dos saberes que esses sujeitos poderiam compartilhar. A professora de Arte, P., levantou algumas questões: "No bairro tinha muitas casas? Havia somente uma rua ou mais? Havia asfalto? E padaria? Como as pessoas chegavam ao supermercado?”. A professora de História, J., trouxe questões sobre o transporte: "Quando não tinha terminal de ônibus, como faziam para ir até o 
centro de Vitória [capital do ES, vizinha à Serra]?". Quando uma das crianças/ adolescentes, C., aventou que carroças poderiam ter sido usadas para esse fim, todos riram, talvez porque isso parecesse, de fato, muito distante de suas experiências.

As 34 crianças/adolescentes se propuseram a identificar no bairro moradores que poderiam participar da roda, trazendo 20 indicações de nomes e respectivos telefones. Em contato feito posteriormente pela pesquisadora, eles se mostravam interessados em participar da atividade, mas, por afazeres pessoais e profissionais, apenas um esteve na roda, o Sr. H., 79 anos, militar reformado, avô da criança/ adolescente M., um dos primeiros moradores do bairro Serra Dourada I.

Outra atividade de preparação para a roda foi a busca por fontes imagéticas da escola, considerando-as como elementos de mediação na complexidade do processo social, reconhecendo a fotografia como "[...] resultado da atividade social, o visível revelado e o invisível oculto, a história sob a aparente simplicidade de uma representação [...]" (CIAVATTA, 2007, p. 35). A fotografia suscita recordações, lembranças de um tempo vivido, pois "[...] o mundo simbólico não é apenas um texto, mas um texto, uma imagem, uma faixa sonora etc. [...]" (ALMEIDA, 2012, p. 27). Assim, as imagens constituem-se em expressões humanas, logo, transmitem algo, podem ser lidas.

A professora de Ciências, A. e a pedagoga, S., se mostraram muito interessadas em falar das memórias vividas na Emef Sonia Regina Gomes Rezende Franco, já que atuavam ali havia alguns anos. A primeira cedeu um caderno de fotografias que ressaltou guardar com muito carinho, o qual continha imagens de eventos dos quais ela havia participado no decorrer de sua trajetória na escola. $A$ pedagoga, por sua vez, trouxe portfólios de fotografias da escola.

O manuseio dessas imagens suscitou recordações: as mobilizações dos profissionais da instituição para obter materiais e melhorar sua precária infraestrutura, os muitos projetos com saídas de campo realizados pela escola e o quanto era bom participar dessas atividades... Ficou perceptível que, mesmo que não aparecessem em algumas fotografias, as duas profissionais sentiam-se parte do processo, corroborando que "[...] nossa memória não se apoia na história aprendida, 
mas na história vivida [...]" (HALBWACHS, 2003, p. 78-79), da qual elas eram partes atuantes.

Posteriormente à exploração do acervo da escola, a turma foi dividida ao meio para a realização de duas rodas de conversa simultâneas, para, com a mediação dessas imagens e ajuda das professoras de História, J., e Arte, P., planejar as atividades que precisaríamos realizar antes e durante a roda de conversa com os moradores. A apreciação das imagens fotográficas gerou deleite de curiosidades, trazendo lembranças acerca da escola e a compreensão de que ela é parte do bairro, ao qual sua história se articula (Imagem 1).



Fonte: acervo da pesquisadora.

Em suas leituras, as crianças/adolescentes produziram narrativas intertextuais, compostas por fatos relacionados a ambos os espaços, direcionadas por suas subjetividades. No decorrer do processo, elas se reconheceram em algumas das imagens (Imagem 2), a partir das quais se lembraram de um projeto de que participaram quando estavam na 1 a série. 
Imagem 2 - Crianças/adolescentes se reconhecem nas imagens da escola

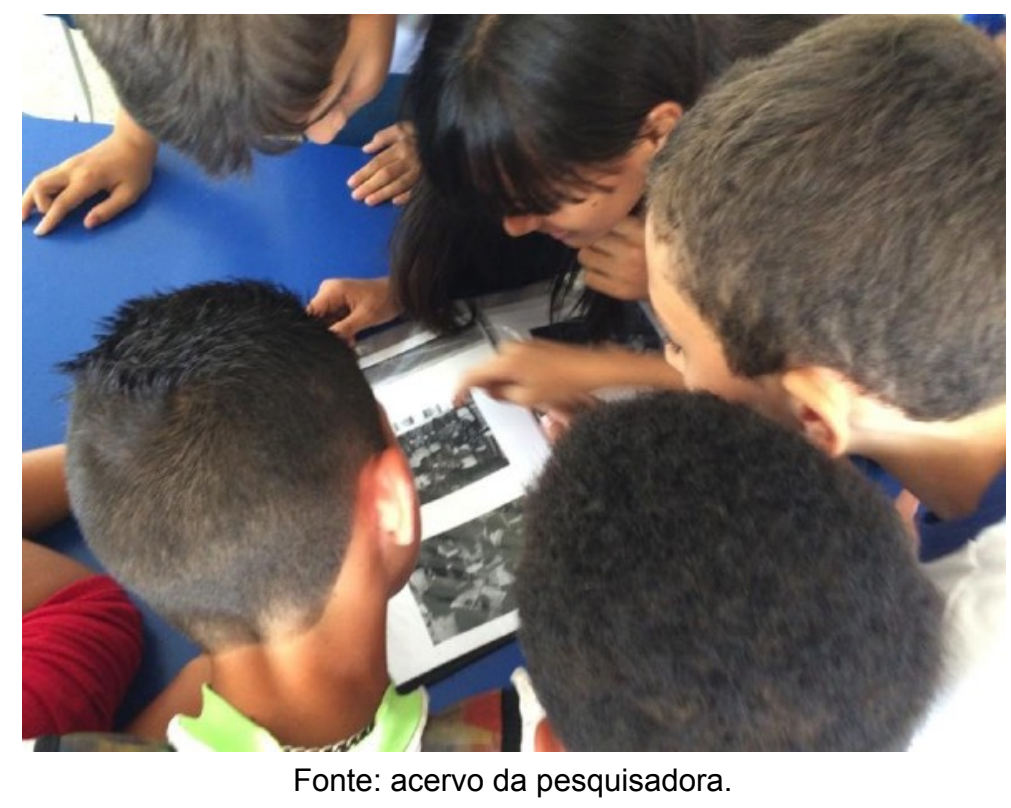

Elas também constataram a mudança na composição da turma ao longo do tempo: alguns chegaram, outros partiram. A partir desse encontro e da partilha das histórias, é possível que cada uma delas tenha produzido uma nova narrativa, conectada às histórias contadas pelos colegas e rememoradas posteriormente. Cada uma narrou suas experiências a partir das lembranças suscitadas, pois em "[...] cada consciência individual as imagens e os pensamentos que resultam dos diversos ambientes que atravessamos se sucedem segundo uma ordem nova e que, nesse sentido, cada um de nós tem uma história [...]" (HALBWACKS, 2003, p. 57).

Entre lembranças e mediações, as crianças/adolescentes demonstraram curiosidades a serem satisfeitas na roda com os moradores. Questionavam-se sobre a denominação, lideranças e configuração do bairro quando de seu surgimento (quantidade de ruas e casas, material usado nas construções, comércio, transporte, iluminação, lazer e recursos naturais). Ainda, interessaram-se em saber sobre os modos de vida (relação das crianças com a natureza, aparelhos eletrônicos então utilizados, nível de violência no bairro). Também queriam saber dos moradores sua origem, motivo e idade com a qual haviam se mudado para o bairro e o que mais Ihes havia chamado a atenção quando ali chegaram. Sobre a escola, formularam perguntas sobre ano de fundação e características de seu primeiro prédio; número de alunos, turmas e coordenadores atuando; seu primeiro diretor, bem como o 
motivo da mudança em sua denominação. A personalidade e a causa da morte de Sonia Regina, professora que hoje dá nome à escola, também foram alvo de curiosidade.

À medida que as crianças/adolescentes iam lançando as perguntas nas rodas de conversa que ocorreram previamente àquela que contou com a presença de um morador, os questionamentos foram registrados pelas professoras de Arte, P., e de História, J. No dia do encontro intergeracional, elas receberam essa lista e ficaram livres para escolher qual dentre as perguntas fariam, podendo incluir outras, à medida que a compartilha aguçasse sua curiosidade.

As narrativas produzidas no encontro intergeracional, portanto, situaram-se em torno do surgimento do bairro e da escola, conectados às imagens e memórias dos sujeitos, contrapondo o antigo e o atual. Guiamo-nos, assim, pela pergunta de Brandão (informação verbal)1, indo além do que está contado nos livros: "[...] o que está por baixo disso e que às vezes a gente não vê quando a gente só vai lá em dia de festa, mas que faz o cerne, o miolo da vida dessa gente? E a sua memória? E a sua história? [...]".

\subsection{A RODA DE CONVERSA INTERGERACIONAL}

A roda de conversa em que foi promovido o encontro intergeracional ocupou uma aula de Educação Física e uma de História e contou com a participação das crianças/adolescentes então matriculados em uma turma de $6^{\circ}$ ano e de adultos profissionais da escola: a pedagoga S.; as professoras de Ciências, Arte e História, respectivamente, A., P. e J.; o diretor, A. Quanto aos participantes externos à escola, além do Sr. H., morador bairro, estiveram na roda uma das autoras; o colaborador do "Grupo de Pesquisa Imagens, Tecnologias e Infâncias" (Ufes), M.; a graduanda em Artes Visuais K., que fez registros fotográficos durante a atividade.

O encontro iniciou-se com a leitura, sugerida pela professora J., de "Caixa de saudade", poesia de Sandra Falcão, já apresentada às crianças/adolescentes em etapa anterior da investigação. J. ressaltou a importância de cultivarmos memórias, mesmo as que nos causaram dor. Sobre tais situações, Benjamin (2012, p. 124)

\footnotetext{
1 Na palestra "Comunidades tradicionais e educação do campo", ocorrida em 10 de agosto de 2016,
} na Universidade Federal do Espírito Santo, Vitória (ES). 
registrou que os soldados voltaram silenciosos do campo de batalha da I Guerra, “[...] mais pobres em experiências comunicáveis, e não mais ricos. Os livros de guerra que inundaram o mercado literário dez anos depois continham tudo, menos experiências transmissíveis de boca em boca [...]", de modo que, sem escuta, muitas histórias ficaram abafadas.

Os álbuns de fotografias da escola e da professora A. foram passando pelas mãos de todos. Em meio à apreciação, T., uma das crianças/adolescentes, endereçou a seguinte pergunta ao Sr. H.: "qual foi a primeira escola do bairro?", ao que ele respondeu: "essa aqui mesmo! Começou lá embaixo [apontando para a sala da direção], onde hoje é a creche.

L. P. quis saber quando foi fundada a escola, ao que o Sr. H. informou que havia sido em 1982. A pedagoga, S., acrescentou que chegou à escola em 1988, quando a unidade passou a também atender aos estudantes de $5^{\mathrm{a}}$ a $8^{\mathrm{a}}$ séries (antigo ginasial), em prédio construído por convênio com uma mineradora da região.

O Sr. H. comentou de sua mudança para o bairro, anos antes, em 8 de novembro de 1982, registrando que ocorreu um temporal, o que alagou muitas ruas. Para Halbwachs (2003, p. 59), certas lembranças não dependem de nossa vontade, "[...] a lembrança está ali, fora de nós, talvez dispersa entre muitos ambientes [...]". Sendo assim, constitui-se parte da narrativa, pois foi significativa para nós. É o que percebemos nesta narrativa do Sr. H.: o temporal, com certeza, trouxe-lhe transtornos e prejuízos, como a preocupação para que a chuva não molhasse seus pertences durante o trajeto, móveis e objetos sendo retirados do transporte e levados à nova moradia debaixo da chuva, ruas alagadas.

A criança/adolescente X. questionou: "como era a pavimentação [do bairro] antigamente?". O Sr. H. relatou que, "toda a vida foi asfalto [...]", ao que a pedagoga, S., lembrou que as casas eram todas iguais. O morador confirmou a informação, acrescentando que em volta das residências, que haviam sido construídas por uma empresa denominada Economiza, "[...] muro não existia. Existia uma cerquinha de ripa". A criança/adolescente C. quis saber "qual foi a primeira quadra de esporte do bairro". O Sr. H. respondeu que havia sido a quadra da própria escola, hoje, ampliada, após reforma. 
Assim, a partir da narrativa oral, as trocas e reflexões se estabeleceram, tendo em vista os (com)textos vividos, expandindo-se para novos/outros modos de se perceber e perceber os acontecimentos atuais, produzindo possíveis mudanças, bem como dando continuidade ao desejo de que elas ocorressem. Com isso, remetemo-nos a Freire (2014, p. 99), quando afirma que, "[...] na medida em que os homens, simultaneamente, refletindo sobre si e sobre o mundo, vão aumentando o campo de sua percepção, vão também dirigindo sua 'mirada' [...]”.

Direcionando-se ao Sr. H., a criança/adolescente R. S. perguntou: "o que mais chamou sua atenção quando chegou no [sic] bairro". Ele destacou "[...] a falta de condução. Tinha uma empresa de ônibus que era da Viação Pernambuco, ela saía daqui do bairro e ia até Viana [município da Região Metropolitana da Grande Vitória - (ES)], era mais difícil do que hoje [...] meus filhos iam a pé até a escola, que era em Mata da Serra [Serra (ES)]". Assim, o morador misturou fatos coletivos e individuais vividos; "[...] ele é o memorizador e das camadas do passado a que tem acesso pode reter objetos que são, para ele, significativos dentro de um tesouro comum" (BOSI, 1994, p. 411).

A criança/adolescente $C L$. indagou em relação à existência de cercados nos terrenos das casas e da escola: "e a escola, sempre teve muros?". Tentando resgatar suas memórias, o Sr. H. indaga-se: "a escola...?". A pedagoga, S., antecipou-se, solicitando-Ihe confirmação: "Era uma cerca, né?". O Sr. H. completou que "era cerca de ripas, como as das casas [...]". A pesquisadora perguntou por que não havia muros, ao que a pedagoga aventou que poderia ser por causa dos animais, lembrando que a cerca "[...] era baixinha, um aramezinho só para [quem estava na rua] não ter acesso [...] com essa cerca, a gente tinha visibilidade para todos os lugares do entorno da escola". O Sr. H. ampliou a descrição do muro: "era um murinho perfeitinho de ripa, pintadinho, certinho [...]".

Ciavatta (2007, p. 68) sublinha que "[...] a memória é parte substancial da vida; ela alimenta a história de cada um, a história dos grupos e dos povos [...]". Nessa perspectiva, demonstrando compreender que a escola é parte do bairro e vice-versa, a criança/adolescente G. mediou a conversa: "qual foi o primeiro nome 
do bairro? Se ele teve outro nome... [...]". Ouviu do Sr. H. que "sempre foi Serra Dourada I [...]".

Com o questionamento de A. L., sobre se "antigamente existiam muitos aparelhos eletrônicos no bairro", o morador contou que, ao se mudar para ali, ele possuía TV e rádio. Já o telefone, poucas pessoas tinham, pois "[...] era aparelho caro", segundo relatou, explicando que, antigamente, para ter um telefone, a pessoa precisava fazer uma assinatura, comprando ações das empresas telefônicas. Os adultos da roda, assim como o Sr. H., lembramos ainda de que estranhamos ao ver alguém usando os telefones públicos, chamados de "orelhões", hoje, quase em desuso, tal como o telefone fixo.

Também houve questionamento sobre os aparelhos eletrônicos existentes na escola à época. A pedagoga contou que "nem telefone fixo, nem orelhão" havia, lembrando que, quando precisavam fazer alguma ligação, "a gente ia na casa do [vizinho] Sr. L. C. [...]. Ele cedia o telefone da casa dele [...] a esposa dele era nossa colega de trabalho". Suprida a demanda por tal tecnologia, hoje, cada escola da Serra (ES) possui um telefone fixo e até celulares, além de tecnologias de informática.

Ainda com a mediação das memórias tecnológicas, a professora A. lembrouse de que "as provas eram rodadas em um mimeógrafo. Vocês não têm ideia! Hoje vocês têm muitas coisas!". A partir disso, S. lembrou-se do cheiro de álcool que ficava nas provas. A professora A. deu outros detalhes sobre esse processo: "[...] a gente pegava o [pape/] estêncil e escrevia. Escrevia a prova toda, depois colocava o estêncil no aparelho e rodava prova por prova [...] depois [...], pegava cada prova e espalhava para secar e depois aplicava a prova”. A mediação imagética permite

[...] rememorar e/ou entender fatos com maior riqueza de detalhes. Ela suscita lembranças, não necessariamente os fatos do momento capturado, mas as conexões a outras memórias, outros fatos, que se presentificam quando apreciamos uma imagem, mesmo que ela não represente um fato vivido. As recordações têm o poder de nos fazer sentir os (com)textos dos quais fizemos parte, podemos sentir cheiros, gostos, texturas... Enfim, inúmeras sensações, como se estivéssemos de fato revivendo as experiências (VAGO-SOARES; SCHÜTZ-FOERSTE, 2015, s/p). 
É importante ressaltar que o interesse das crianças/adolescentes pelas tecnologias antigas havia sido notado em fase anterior da investigação, em visitapasseio ao museu da cidade, onde elas se encantaram com uma máquina de escrever. A pesquisadora rememorou fatos sobre o objeto, relatando que o havia usado para redigir cartas e poesias. Interessadas, as crianças/adolescentes fizeram vários questionamentos, estabelecendo relações entre a máquina e o computador.

No encontro intergeracional, os adultos narramos sobre algumas particularidades da máquina de datilografar, explicando que a cada erro cometido era preciso começar tudo de novo, ou o documento ficaria rasurado, com uso de borrachas ou corretivos. Logo, tratava-se de um modo de escrever diferente do comumente utilizado hoje, com os computadores, celulares, tablets, que tornam tais situações impensáveis para as novas gerações.

A professora A. ressaltou ainda que houve um tempo em que a escola não possuía televisão, sendo usado apenas quadro, "[...] ruim, caindo aos pedaços, e giz". A falta de equipamentos básicos, segundo ela, gerou mobilização. Sonia Regina, educadora que dá nome à unidade, criou uma bem-sucedida campanha de arrecadação de latas de refrigerante para trocá-las por ventiladores, segundo contou a professora A., justificando o sucesso da ação: "os professores eram bem engajados".

A. se recordou, ainda, de outra conquista do grupo. Segundo relatou, muitos alunos se sentavam no chão, em mesa quebrada...; "[...] aquilo foi doendo no nosso coração [...] E fomos à Prefeitura da Serra, todos nós [professores], juntos! Um povo unido faz a diferença! Chegamos lá e ficamos esperando [cruzou os braços, demonstrando que ficaram lá até resolver a situação]". No dia seguinte, caminhões da Prefeitura Serra levaram carteiras novas à escola.

Com o crescimento do número de alunos, a pedagoga, S., lembrou que, ao chegar à escola, para atender à demanda, o dia letivo foi organizado de forma diferente do que ocorre hoje, tendo três turnos: $7 \mathrm{~h}$ às $10 \mathrm{~h}, 11 \mathrm{~h}$ às $15 \mathrm{~h}$ e 15 às $19 \mathrm{~h}$. Relações entre o presente e o passado produzem " [...] corpo social, cuja pluralidade provoca novas discursividades [...]” (ARAúJO, acesso em 21 fev. 2016, grifo nosso), que se materializa na produção de narrativas, sabendo que 
[...] a memória permite a relação do corpo presente com o passado e, ao mesmo tempo, interfere no processo 'atual' das representações. Pela memória, o passado não só vem à tona das águas presentes, misturando-se com as percepções imediatas, como também empurra, 'desloca' estas últimas, ocupando o espaço da consciência. A memória aparece como força subjetiva ao mesmo tempo profunda e ativa, latente e penetrante, oculta e invasora (BOSI, 1994, p. 46-47).

Nas (re)leituras, as narrativas produzidas pelas crianças/adolescentes foram perpassadas pela subjetividade, já que não lhes é transmitida "[...] apenas uma cultura constituída que Ihes atribui um lugar e papéis sociais, mas [as crianças/ adolescentes] operam transformações nessa cultura, seja sob a forma como a interpretam e integram, seja nos efeitos que nela produzem, a partir das suas próprias práticas [...]" (VASCONCELLOS, 2008, p. 29).

A pedagoga ressaltou que ex-alunos voltam à escola para rever os profissionais com os quais conviveram e que alguns dos que cursam licenciatura na graduação a escolhem para fazer estágio. A professora de Arte, P., ressaltou, inclusive, que entre os professores da escola há ex-alunos, mostrando o carinho que estes têm pela escola, pois "[...] retornam para ajudar [...]". Logo, as narrativas demonstraram afeto pelo espaço escolar.

A escola e o bairro se encontraram nessa dinâmica e as memórias suscitaram reflexões sobre a convivência e sentidos que os estudantes atribuem aos espaços em que estão, pois "[...] lembrar não é reviver, mas re-fazer. É reflexão, compreensão do agora a partir do outrora; é sentimento, reaparição do feito e do ido, não sua mera repetição [...]" (BOSI, 1994, p. 20). Assim, narrar é pensar em algo que se produz com imagens e memórias, tornando vivas as narrativas de um tempo passado, conectando-o ao hoje.

No desenrolar dos diálogos, a criança/adolescente L. P. questionou ao morador se "havia muita violência no bairro e na escola". Subtenente militar reformado, o Sr. H. explicou que esse problema era menos frequente que hoje, quando "temos muita droga presente no bairro, que gera violência". L. S., por sua vez, quis saber do morador o motivo que o levou a se mudar para o bairro, ao que este explicou que, antes, morava em Vitória (ES), perto do Quartel da Polícia Militar, 
quando surgiu a oportunidade se inscrever para conseguir a casa no bairro, preferência dada aos policiais. Por isso, não demorou e ele foi contemplado, mudando-se para ali. O Sr. H. também se recordou de uma época em que muitos moradores abandonaram as casas, com o que ocorreram invasões. A pedagoga, S., destacou que sua chegada à escola Sonia Regina foi nesse período, reiterando que foi um momento conturbado.

Percebemos que as histórias de vida dos sujeitos se misturaram com as memórias e imagens da escola, do bairro. Na medida em que as narrativas são construídas, notamos que as histórias se encontram, se cruzam, se afinam ou desafinam com outros (com)textos, desencadeando-se em narrativas outras, nesse tempo e espaço. Isso porque, do mesmo jeito que não se lê um livro duas vezes do mesmo modo, não há como narrar uma história da mesma maneira (BOSI, 1994) ou, como lembra Benjamin (2012, p. 221), “[...] contar histórias sempre foi a arte de contá-las de novo, e ela se perde quando as histórias não são mais conservadas $[\ldots] "$.

Nos possíveis esquecimentos e lembranças, as histórias foram produzidas e, de maneira inacabada, ficam disponíveis para novas elaborações. Segundo Benjamin (2012), se não é possível contar histórias sem a preocupação de contar aquilo que o outro quer escutar, os contos subjetivos se perdem em meios a tantos outros que já estão postos, seja nos livros didáticos, seja nos jornais, seja em outros materiais impostos pelos sistemas. Ainda segundo este pensador, a história "[...] se perde porque ninguém mais fia ou tece enquanto [a] ouve [...]" (BENJAMIN, 2012, p. 221). Assim, mesmo que não contemos as histórias, elas podem e devem estar imbricadas às práticas desenvolvidas na escola, tendo em vista a mistura das histórias de vida de seus protagonistas, que se articulam aos conteúdos de ensino estabelecidos, sendo entendidas como fontes históricas.

A criança/adolescente G. mostrou ao diretor, A., uma fotografia de 2008 e perguntou se quando este chegou à unidade "a escola era assim". O diretor salientou que não, acrescentando que o formato da unidade lhe pareceu estranho, pois "[...] não era um prédio normal, eram umas casinhas [...], mas foi paixão à primeira vista [...]. Dei aula até 2012. Tive oportunidade de me candidatar nesse ano. 
Fizemos uma chapa, a chapa 1 [...]", com a qual ele chegou à direção, sobre o que G. também havia demonstrado curiosidade. O diretor explicou que, por imprevistos burocráticos, a eleição só ocorreu em abril de 2013. Destacou, ainda, que, em sua opinião,

[...] a escola precisa melhorar muito ainda, principalmente na parte estrutural, a gente não consegue resolver tudo, depende da Prefeitura [...] sinto que o grupo de professores é excelente! Eles têm um amor pela escola muito grande. Os pedagogos, os coordenadores, professores, alunos... [...].

O diretor observou que, mesmo com a grande quantidade de alunos, os professores são bastante dedicados à escola. E completou que "[...] quem faz a escola ficar boa não é o diretor, não é o coordenador... É todo mundo. Todo mundo que demonstra seu amor, sua dedicação pela escola faz com que a escola fique boa $[\ldots] "$.

Concluímos a roda de conversa lamentando o fato de o tempo ter sido breve (das $7 \mathrm{~h}$ às $9 \mathrm{~h}$ ) e ressaltando que poderíamos ficar uma manhã inteira ali... Logo, G. manifestou-se em voz alta: "Eu gostaria!". Refletindo sobre o desejo manifesto por esta criança/adolescente, entendemos que conhecer nossas histórias é, de fato, algo prazeroso, em que se aprende para além de conteúdos e conceitos preestabelecidos ou ditos formais. As narrativas dos sujeitos da escola foram elaboradas de forma dinâmica, não linear, imbricadas às memórias e imagens com que cada uma delas estabeleceu diálogos, pois

[...] para que a nossa memória se aproveite da memória dos outros, não basta que estes nos apresentem seus testemunhos: também é preciso que ela não tenha deixado de concordar com as memórias deles e que existam muitos pontos de contato entre uma e outras [...] (HALBWACHS, 2003, p. 39).

Compreender como as narrativas se elaboram é desafiador, pois o processo de produção interpretativa é singular, porque produzido por cada sujeito, de maneira única. Logo, "[...] todos os dados psíquicos e culturais apenas existem realmente na medida em que são produzidos e reproduzidos no presente: daí a experiência somente ser relevante ao ser concretamente incorporada ao presente 
[...]" (MANNHEIM, 1952, p. 71, tradução nossa). Essa apropriação surge a partir do conhecimento do passado e também de como cada sujeito dele se apropria e faz uso no presente.

A roda de conversa em que se deu o encontro intergeracional ocorreu no fim do ano letivo, encerrando a etapa de exploração daquele cotidiano escolar e de algumas narrativas ali produzidas. Como pudemos perceber, essa atividade possibilitou as trocas das crianças/adolescentes com alguns adultos que participaram dos momentos históricos e sociais da fundação do bairro e da escola.

O encontro intergeracional ocorreu de modo particular, pois "[...] os dados experienciais, intelectuais e emocionais à disposição dos membros de uma certa sociedade não são uniformemente 'dados' a todos eles; [...] cada classe tem acesso apenas a um conjunto daqueles dados, restrito a um 'aspecto' [...] (MANNHEIM, 1952, p. 73, tradução nossa). Acontece assim, pois imagens e memórias vêm à tona quando nos permitimos acessá-los mentalmente ou em forma de fotografias, artefatos etc. A partir disso, se encontram, se cruzam entre as narrativas de cada pessoa disposta a estabelecer diálogos.

Tal como Schütz-Foerste (2004), entendemos que as imagens são expressões do homem, contam histórias localizadas e datadas. Como também ocorre com as memórias, as imagens se encontram em espaço privilegiado, o da linguagem humana, e "[...] cada geração tem, de sua cidade, a memória de acontecimentos como pontos de demarcação em sua história [...]" (BOSI, 1994, p. 418), que se elaboram à medida que são partilhadas, contadas e recontadas.

Nessa perspectiva, a roda de conversa constituiu-se em espaço de reflexão, processo de ir e vir, girando para todos os lados em que havia o desejo de compartilhar. Constituiu-se em possibilidade de exercitar a escuta e a fala, de saber que todos protagonizam a cena e podem direcionar as discussões nos imbricamentos das imagens e das memórias, narrativas que se articulam e se produzem. Promoveu sentimento de inclusão, não apenas nas crianças, portadoras da ideia de promovermos a conversa com os moradores do bairro; a elas foram dados voz e ouvidos nesse movimento, como também ao $\mathrm{Sr}$. $\mathrm{H}$. O morador chegou à roda programado para participar da conversa apenas por determinado tempo. 
Entretanto, sentindo-se ouvido e valorizado em suas memórias, acabou permanecendo até o fim. Além disso, conforme sua neta, M., "[...] contou tudinho [...]" para a esposa sobre como havia transcorrido a atividade, o que evidencia que as narrativas não cessaram.

Retomando a perspectiva de Freire (2014), que a denomina como círculo de cultura, a roda de conversa foi momento de aprendizagem em que todos do círculo se olharam e se viram, indo além do aprender só; foi momento de trocas, no qual modos de ser, pensar e agir no mundo foram ensinados, mas também aprendidos.

\section{CONSIDERAÇÕES FINAIS}

Etapa de um projeto de ensino da Arte a partir do qual uma investigação de doutorado foi empreendida ao longo de três semestres letivos, a experiência aqui relatada configurou-se como processo de produção de narrativas vivenciado por crianças, adolescentes, adultos e velhos em roda de conversa, a qual, portanto, constituiu-se em encontro intergeracional.

Esse processo baseou-se em imagens e memórias de uma escola pública de ensino fundamental e do bairro em que ela se situa e reforçou que as narrativas são histórias e composições que requerem o exercício da memória e da imaginação, para extrair e captar a síntese. Aqui, cabe ratificar que todos os textos imagéticos são pertinentes para esta reflexão, porque as imagens trazidas traduzem uma metaanálise da experiência vivida.

Os participantes das diversas gerações estabeleceram-se como protagonistas da conversa, disponibilizando-se a si, suas histórias e suas memórias, favorecendo o compartilhamento das narrativas no espaço escolar. No encontro em roda, puderam oferecer sua fala e escuta, ensinar e aprender, em especial, acerca de processos sociais e culturais vividos em diferentes tempos e espaços.

A experiência sublinhou a escola como lugar de diversidade, repleta de culturas, de imagens e memórias que se produzem nas interações de crianças e de adultos, em momentos de ensinar e aprender, simultaneamente, protagonizando as práticas docentes e discentes. Nesse sentido, a escola deve, pois, ser entendida 
como lugar de trocas, de compartilhamento de imagens e memórias, incluindo também as cultivadas pelos velhos que habitam o bairro e a cidade.

Realizada na perspectiva da valorização dos encontros intergeracionais, as rodas de conversa configuram-se como rica oportunidade para que os sujeitos possam se apropriar de imagens e memórias de um tempo que eles próprios não vivenciaram, mas que podem fazê-las suas, se partilhadas por personagens de gerações anteriores.

Para os atores que vivenciam a fase da velhice, por sua vez, as conversas intergeracionais são ricas oportunidades de deslocá-los das margens da sociedade, dando relevo às suas memórias, culturas e imagens, com as quais crianças/ adolescentes podem aprender sobre os lugares que habitam, sobre o outro e sobre si mesmos.

\section{REFERÊNCIAS}

ALMEIDA, J. Textualidades contemporâneas: palavra, imagem, cultura. Vitória: Edufes, 2012.

ARAÚJO, V. C de. A cidade como espaço público de educação e de afirmação da cidadania: a experiência de Vitória/ES-Brasil. Disponível em: <http://www.anpae.org.br/ iberolusobrasileiro2010/cdrom/120.pdf>. Acesso em: 21 fev. 2016.

Ética e estética: tecendo um olhar a partir da criança. Cadernos de Pesquisa em Educação, Vitória, v. 11, n. 22, p. 107-120, jul./dez. 2005.

ASSIS, C. E de. Fios de temporalidades na educação infantil. 2012. Disponível em: <http://35reuniao.anped.org.br/images/stories/trabalhos/GT07\%20Trabalhos/ GT07-1658_int.pdf>. Acesso em: 14 jan. 2019.

BENJAMIN, W. Escritos sobre mito e linguagem. 2. ed. São Paulo: Duas cidades, 2013.

Magia e técnica, arte e política: ensaios sobre a literatura e história da cultura. 8. ed. São Paulo; Brasiliense, 2012.

BOSI, E. Memória e sociedade: lembranças de velhos. 3. ed. São Paulo: Companhia das Letras, 1994.

BRANDÃO, C. R. A pergunta a várias mãos: experiência de pesquisa no trabalho do educador. São Paulo: Cortez, 2003.

Documentário: cultura popular e educação. Entrevista concedida em 2007 à TV Brasil. Disponível em: <http://www.tvbrasil.org.br/saltoparaofuturo/entrevista.asp? cod_Entrevista=34>. Acesso em: 12 jan. 2015. 
Loyola, 1984.

Pensar a prática: escritos de viagem e estudos sobre educação. São Paulo:

BRASIL. Ministério da Educação. Secretaria de Educação Básica. Diretrizes Curriculares Nacionais para a educação infantil. 2010. Disponível em: <http://portal.mec.gov.br/ index.php? option=com_docman\& vie w = download \& alias = 9769 diretrizescurriculares-2012\&category_slug=janeiro-2012-pdf\&ltemid=30192>. Acesso em: 5 mar. 2016.

CAMARGO, F. M. B. Memórias imagéticas: revisitando as narrativas infantis em contexto escolar de ensino fundamental. Tese (Doutorado em Educação) -Universidade Federal do Espírito Santo, UFES, 2014.

CIAVATTA, M. Do espaço da fábrica para o espaço da escola (I): introdução a uma história fotográfica. In: CIAVATTA, M.; DUARTE, E. T. et al. (Orgs.). Memória e temporalidades do trabalho e da educação. Rio de Janeiro: Lamparina; Faperj, 2007. p. 41-72.

Mediações históricas de trabalho e educação: gênese e disputas na formação dos trabalhadores (Rio de Janeiro 1930-60). Rio de Janeiro: Lamparina, CNPq, Farpej, 2009.

DUARTE, N. Lukács e Saviani: a ontologia do ser social e a pedagogia histórico-crítica. In: SAVIANI, D.; DUARTE, N. (Orgs.). Pedagogia histórico-crítica: primeiras aproximações. Campinas: Autores Associados, 2012. p. 37-57.

FONSECA DA SILVA, M. C. da R.; SCHLICHTA, C. A. B. D. Laptop na escola: das tecnologias às imagens na sala de aula. Disponível em: <http://37reuniao.anped.org.br/wpcontent/uploads/2015/02/Trabalho-GT24-4619.pdf>. Acesso em: 19 fev. 2016.

FREIRE, P. Ação cultural para a liberdade e outros escritos. 14. ed. Rio de Janeiro: Paz e Terra, 2011.

A importância do ato de ler. São Paulo: Cortez, 1995.

Pedagogia do oprimido. 56. ed. Rio de Janeiro: Paz e Terra, 2014.

HALBWACHS, M. A memória coletiva. São Paulo: Centauro, 2003.

MANNHEIM, K. O problema da 'intelligentsia': um estudo de seu papel no passado e no presente. In: (Org.). Sociologia da cultura. 2. ed. São Paulo: Perspectiva, 2004. p. 69-139.

MANNHEIM, K. The sociological problem of generation. In: sociology of knowkdge. Londres: Routtdge \& Kegan Paul, 1952. p. 286-312.

Essays on the

OLIVEIRA, R. C. de. O trabalho do antropólogo: olhar, ouvir, escrever. Revista de Antropologia, São Paulo, USP, v. 39, n. 1, p. 13-37, 1996.

ROSA, J. A. V da. Infância, experiência e racionalidade: um estudo no ambiente escolar. Dissertação (Mestrado em Educação) - Universidade Federal do Espírito Santo, UFES, 2011.

SCHÜTZ-FOERSTE, G. M. Contribuições de Lukács na pesquisa com imagens na educação: um breve estudo das categorias trabalho, particularidade e mediação. In: FICHTNER, B. et al. (Orgs.). Cultura, dialética e hegemonia: pesquisas em educação. 2. ed. Vitória: Edufes, 2013. p. 187-201. 
2004.

Leitura de imagens: um desafio à educação contemporânea. Vitória: Edufes,

SARMENTO, M. J. As culturas da infância nas encruzilhadas da $\mathbf{2}^{\mathbf{a}}$ modernidade. Disponível em: <http://www.cedei.unir.br/submenu arquivos/ 761_1.1_u1_as_culturas_na_infancia.pdf>. Acesso em: 10 mar. 2017.

Gerações e alteridade: interrogações a partir da sociologia da infância. Educação e Sociedade, Campinas, v. 26, n. 91, p. 361-378, maio/ago. 2005.

Imaginário e cultura da infância. Instituto de Estudos da Criança da Universidade do Minho, Portugal, 2003. Disponível em: <http://cedic.iec.uminho.pt/Textos_de_Trabalho/ textos/ImaCultInfancia.pdf>. Acesso em: 13 nov. 2010.

SAVIANI, D. Marxismo, educação e pedagogia. In: SAVIANI, D.; DUARTE, N. (Org.). Pedagogia histórico-crítica: primeiras aproximações. Campinas: Autores Associados, 2003. p. 59-85.

SIQUEIRA, R. M. Do silêncio ao protagonismo: por uma leitura crítica das concepções de infância e criança. Tese (Doutorado em Educação) - Faculdade de Educação, Universidade Federal de Goiás, Goiânia, 2011. Disponível em: <https://ppge.fe.ufg.br/up/6/o/ TESE_Romilson_Martins_Siqueira.pdf. 1335451613>. Acesso em: 25 jan. 2016.

VAGO-SOARES, M. A.; SCHÜTZ-FOERSTE, G. M. Interculturalidade: culturas e práticas educativas que afinam e desafinam. In: ENCUENTRO DE LAS CIENCIAS HUMANAS Y TECNOLÓGICAS PARA LA INTEGRACIÓN DE LA AMÉRICA LATINA Y EL CARIBE INTERNACIONAL DEL CONOCIMIENTO: DIÁLOGOS EN NUESTRA AMÉRICA, 3., 2015, Goiânia.

VAGO-SOARES, M. A. Infância, arte e cultura: experiências em (com)textos educativos. São Carlos: Pedro \& João, 2015.

VASCONCELLOS, V. M. R. Apresentação: infâncias e crianças visíveis. In: VASCONCELLOS, V. M. R.; SARMENTO, M. J. (Orgs.). Infância (in)visível. Araraquara, SP: Junqueira \& Marin, 2007. p. 7-23.

Infância e psicologia: marcos teóricos da compreensão do desenvolvimento da criança pequena. In: SARMENTO, M.; GOUVEA, M. C. S. de. (Orgs.). Estudos da infância: educação e práticas sociais. Petrópolis: Vozes, 2008. p. 62-81.

VÁSSINA, E. Nikolai Leskov, o mais original dos escritores russos. In: LESKOV, N. A fraude e outras histórias. São Paulo: Editora 34, 2012. p. 203- 217.

VIGOTSKI, L. S. Psicologia pedagógica. 3. ed. São Paulo: Martins Fontes, 2010. 